\title{
Judith y Holofernes de Antonio de Pereda: una excepcional representación de poder femenino en la pintura española del siglo XVII
}

\author{
Begoña Álvarez Seijo \\ Universidad de Santiago de Compostela \\ b.alvarez.seijo@usc.es
}

En la producción pictórica del Barroco español la cantidad de temas dedicados al Antiguo Testamento es exigua y los motivos que conducen a esta laguna de representación son múltiples y dispares (Calvo, 1988: 135-158). Por un lado, su fuerte contenido simbólico y su inducción a profundas y complicadas reflexiones no los convertía en adecuados para la inmediatez en el despertar del sentimiento devocional que buscaba el pensamiento nacido tras el concilio tridentino; por otro lado, estas historias podían concurrir en contradicciones con la férrea ortodoxia de la Iglesia, tanto por su relación con el judaísmo y la historia de Israel (Marías, 2016: 443-445), como por la defensa que de estos pasajes hacía el pensamiento luterano. Asimismo, en el caso concreto de las mujeres fuertes de la Biblia, se puede esgrimir un tercer argumento igual de poderoso: algunas de las virtudes que personifican -fortaleza, valentía, constancia, inteligencia- no eran aquellas que se pretendían imponer como propias del género femenino por parte del humanismo cristiano, tan prolífico en sus manuales de conducta para mujeres desde la segunda mitad del siglo XVI y durante los siglos XVII y XVIII. De este modo, a pesar de su función como prefiguraciones marianas, su representación es limitada en la plástica española del siglo XVII y los ejemplos que encontramos firmados por nuestros artistas o bien se encuentran apartados del ojo público -en la intimidad de las alcobas palaciegas u ocultos tras los muros de la clausura- para la educación de las mujeres de alta alcurnia y cultura elevada, o se trata de lienzos que escogen un pasaje de sus historias que atenúan las facultades de las heroínas hebreas, aquellas que no se correspondían con la esencia del ideal femenino que se pretendía imponer. El lienzo de Judith y Holofernes de Antonio de Pereda, dado a conocer por el profesor Angulo (1957: 125-126), es una excepción que contradice la regla, tanto por la temática escogida como por la forma de ejecutarla.

En este sentido, lo más relevante de la biografía de Pereda es dónde tuvo lugar su formación artística y qué posibles vínculos puede tener dicho aprendizaje en el arte de la pintura con la consecución de obras un tanto excepcionales «por su asunto y por la intensidad conseguida» (Angulo y Pérez, 1978: 156-157), como lo es la obra que aquí nos ocupa ${ }^{1}$. Antonio de Pereda y Salgado nace en Valladolid en el año 1611 (Urrea, 1976: 336-337), y contó con una temprana formación pictórica en el taller de su padre, pintor de segunda fila, pero su pronto fallecimiento en 1622 (Martí y Monsó, 1992: 512), conduce a que el artista se traslade a Madrid. En la villa continúa su formación en el taller de Pedro de las Cuevas ${ }^{2}$, aunque pronto pasará el joven Pereda a estar bajo la tutela del oidor del Consejo Real Francisco Tejada, coleccionista y mecenas quien, según Carducho, poseía una importante cantidad de pinturas en su casa, hablando incluso de un pequeño museo (Angulo y Pérez, 1983: 140). De la protección de Tejada lo sacó el mecenazgo de una importante figura en la vida cultural madrileña, la del Marqués de la Torre, Juan Bautista Crescenzi (Cherry, 1987: 299-306), cuya tutela será decisiva en la formación del pintor. Su origen noble italiano y su amplísimo nivel cultural, gran amante de las artes que él mismo practicaba, condujo a Pereda a entrar en un círculo dónde se debatían e investigaban las tendencias estéticas más avanzadas y le puso en contacto con el ambiente cortesano (Angulo y Pérez, 1983: 140-141). Sin embargo, la muerte de Crescenci en 1635 le cierra las puertas de palacio a un joven y talentoso Pereda, quien no vuelve a trabajar para la corte (Aterido, 1997: 276). A partir de ese momento Pereda se vuelve hacia la única clientela posible, la eclesiástica, convirtiéndose en un pintor de devoción, sin 


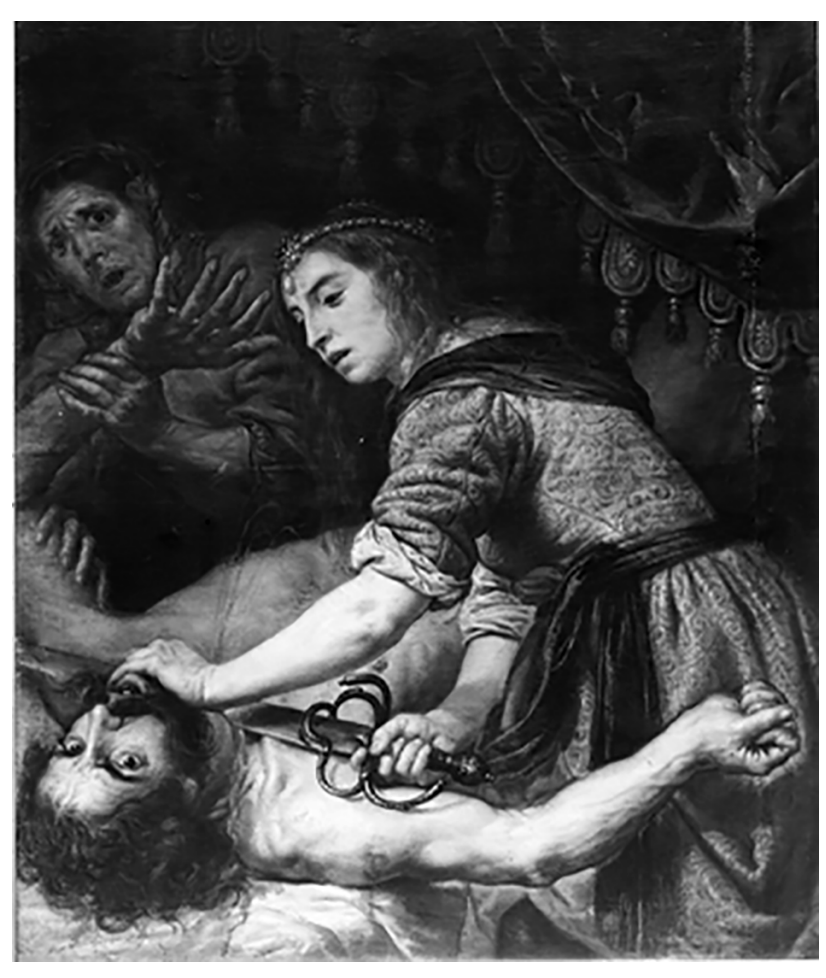

1. Antonio de Pereda y Salgado, Judith y Holofernes. Fotografía del IPCE

otra salida profana que la pintura de naturaleza muerta y la pintura alegórica moral, de fácil venta entre la burguesía y en la baja nobleza (Angulo y Pérez, 1983: 142-144).

A pesar de todo, la estancia de Pereda con Crescenzi, entre 1632 y 1635, será determinante; solo es necesario un simple acercamiento a algunos nombres que estuvieron también bajo la protección o promoción del Marqués de la Torre o de su familia, para comprobar la diversidad de su gusto artístico y las diferentes corrientes que pudieron afectar a un todavía joven Pereda ${ }^{3}$. Amante desde época muy temprana del naturalismo caravaggista, del colorido veneciano y de las naturalezas muertas (Blanco, 1998: 194-195), la colección de pinturas, libros, bocetos y documentos relacionados con el arte que Crescenzi poseyó, pudo ser crucial para que un artista como Antonio de Pereda, que nunca salió de España, desarrollase tipos y temas iconográficos tan inusuales, con la expresividad y crudeza, de marcado carácter tenebrista, como el que presenta el cuadro de Judith y Holofernes.

De este lienzo, que mide 1,23 x 1,05 (Valverde, 1978: 207), no se conoce su paradero actual, teniendo constancia de él gracias a la fotografía que se conserva, perteneciente al Fondo Moreno del Instituto de Patrimonio Cultural de España y realizada con anterioridad al año 1938 [1] ${ }^{4}$. Las tres figuras, la heroína Judith, el general Holofernes y la criada Abra, ocupan las tres cuartas partes del lienzo, dejando libre tan solo un pequeño espacio en el que cuelga un oscuro cortinaje que se recoge sobre la esquina superior derecha, para dejarnos contemplar, con pinceladas de teatralidad, la sanguinaria escena principal. El momento escogido por el pintor es el preciso instante en el que la protagonista de Betulia está degollando con el filo de su espada el cuello del general, mientras en un segundo plano, la criada Abra, con gesto de horror, sujeta el brazo izquierdo de Holofernes para ayudar a su ama a cumplir su propósito. Compositivamente es una escena dramática en la que los personajes están magistralmente dispuestos en una diagonal en la que se ordenan los diferentes planos, destacando en primer término a la pareja protagonista, al colocarse sobre ellos el foco de luz al tiempo que se arrincona a la sirvienta a la negrura del fondo. La crudeza de la escena es innegable, desde la decisión y poderío de la disposición del cuerpo y el semblante de Judith, al terror de la faz de Abra o el torrente de sangre que mana del cuello de Holofernes, poseen un realismo que estremece ante lo violento de la acción. Probablemente, el rostro del general, boca arriba y de espaldas al lecho, sea uno de los únicos elementos que nos alejen de ese naturalismo tenebrista en el que nos introducen los personajes femeninos. En conjunto, la escena es enérgica y trata de ser realista en la plasmación de los sentimientos que dominan a los protagonistas de una situación semejante, moviéndose entre la firmeza y el deber, y el horror y espanto ante el acto que se está cometiendo (Angulo, 1957: 125-126).

Esta estructura de escena y disposición de figuras en el tema no es original de Pereda, pues es un modo de composición típica en las representaciones de la historia de Judith: desde la serena escena de Giorgio Vasari, de hacia 1554, del Sant Louis Museum, en Missouri, Estados Unidos, pasando por las diferentes versiones del tema veterotestamentario de Caravaggio, Artemisia Gentileschi y sus seguidores, como la Judith y Holofernes de Valentin Bolougne, fechada en 1626, hoy en el National Museum of Fine Arts de Malta. Sin embargo, y a pesar de la similitud compositiva del lienzo de Pereda con estas escenas, seguramente el modelo en el que se basó el pintor de Valladolid provenga de los grabados flamencos e italianos que tan abundantes eran en la época, 
y que circulaban entre los pintores de nuestro país; además, en Pereda queda patente esta influencia en la elección de los temas para sus telas en obras como Lamentación sobre el Cristo muerto, que tiene su inspiración directa en el grabado homónimo del holandés Jacob Matham, o las estampas italianas de los discípulos de Guido Reni, protegido además de su mentor Crescenzi, como Simone Cantarini (Navarrete, 2008: 65-70). En este caso, el Rijksmuseum de Ámsterdam conserva una estampa del grabador holandés Meynert Jelissen, de hacia 1610-1614, Judith cortando la cabeza a Holofernes, cuyas similitudes con la Judith y Holofernes de Pereda son innegables [2] [ $^{5}$ la disposición de los personajes, el cortinaje recogido en la parte superior, el peinado y los detalles de adorno en la cabellera de la heroína e incluso el horror congelado en el rostro del general Holofernes, inducen a pensar que un grabado como este pudo servir de base para que Pereda comenzase a crear esta obra. Sin embargo, aunque mire compositivamente hacia Flandes, supo dotarlo estilísticamente de un mayor naturalismo, de gran expresividad, en el que los rostros de los personajes miran hacia las formas del barroco italiano, inspirándose en las figuras de Guido Reni o Bartlomeo Cavarozzi ${ }^{\text {. }}$

En lo relativo a su cronología lo cierto es que los tipos femeninos de Pereda son recurrentes a lo largo de toda su producción pictórica ${ }^{7}$, circunstancia que plantea serios problemas a la hora de datar su obra a través de sus modelos y tipos iconográficos (Valverde, 1978: 207; Angulo y Pérez, 1983: 157). En este sentido, cabe destacar que Pereda cuenta dentro de su producción pictórica con otra mujer fuerte: la Susana y los viejos que aparece en el inventario de Manuel Ponce de León, duque de Arcos, realizado en 1693 por Alonso del Arco $^{8}$ (Burke y Cherry, 1997: 967). Lamentablemente, debido a que no aparece fechada en el inventario y que no se conoce su paradero ni se conserva imagen alguna del lienzo, resulta imposible dilucidar si la representación de este otro personaje femenino veterotestamentario seguiría una línea iconográfica y estilística tan sugerente como la que se aprecia en la pintura de la viuda de Betulia, o si ambas podrían haber sido realizadas en fecha próxima.

Sea como fuere, e independientemente de su cronología, esta obra de Antonio de Pereda es uno de los más llamativos lienzos sobre el tema de la heroína bíblica que se encuentran en la producción pictórica del barroco español durante el siglo XVII. En la mayor parte de las obras de esta

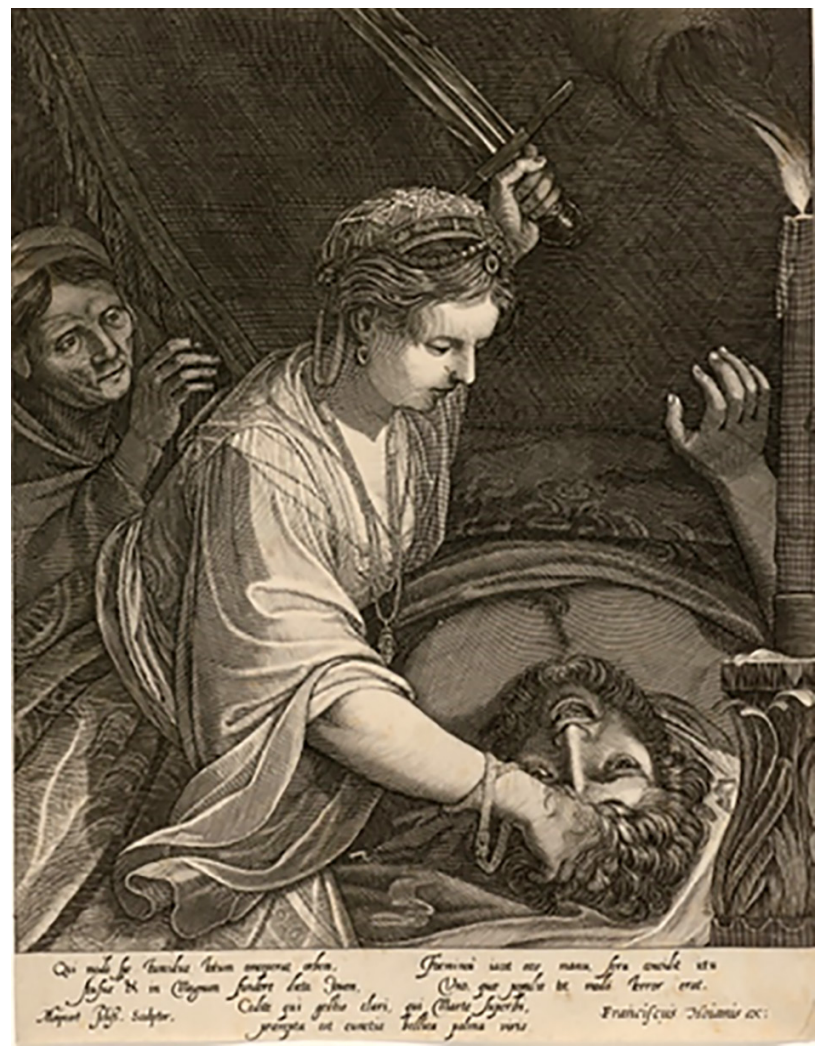

2. Meynert Jelissen, Judit hakt het hoofd van Holofernes af, 1610-1614. Fotografía del Rijksmuseum, Ámsterdam

temática que nos encontramos en la producción pictórica de los pintores españoles del Siglo de Oro, el momento escogido de la historia suele ser el inmediatamente anterior a la degollación del general Holofernes o el posterior, con Judith portando la cabeza y la espada; sin embargo, la obra Pereda nos sitúa en el centro de la acción, en el momento principal del relato bíblico, en el que la joven viuda salva a su pueblo con valentía, astucia y coraje; además, se trata de una de las obras en las que «la escuela madrileña pulsa con mayor éxito la cuerda trágica, armonizando con indudable éxito, composición, mímica y claroscuro" (Angulo, 1957: 126). Por lo tanto, estamos ante una obra singular tanto por el tema escogido como por el modo de representarlo, cuyo estudio puede aproximarnos más a la realidad de un pintor inusual de la escuela madrileña, que ajeno a la corte y teniendo como principal clientela a la Iglesia, pintó algunos lienzos con asuntos que se alejan del gusto impuesto por la cultura del Barroco y sobre los que se debería continuar investigando. 


\section{Notas}

1 Para una biografía completa del autor véase: Palomino, 1988: 303-307; Tormo, 1916; Pérez, 1978; Valverde, 1978; Angulo y Pérez, 1983; Urrea, 1995; Urrea y Valdivieso, 2017.

2 Para mayor información sobre el maestro Pedro de las Cuevas, véase Cruz, 1997: 365-382.

3 II Pomarancio, il Cavalliere d'Arpino, Guido Reni, Claude Lorrain, Bartolomeo Cavarozzi, Van der Hamen, Juan Fernández Labrador Paul Brill, Gaspare Celio, Pietro Paolo Bronzi o Annibale Carracci. Blanco, 1998: 196; Aterido, 1997: 274.

4 Agradezco a Isabel Argerich y al IPCE por su disponibilidad y diligencia a la hora proporcionarme la fotografía que ilustra el presente artículo.

5 Agradezco al Rijksmuseum el haberme facilitado la imagen y sus derechos de reproducción para la realización de este artículo.

6 Debe tenerse en cuenta que Antonio de Pereda, a pesar de haber sido presentando por Palomino como un pintor iletrado, contaba con una importante colección de pintura, libros, estampas, dibujos, grabados, etc. Palomino, 1988: 306; Aterido, 1997: 282.

7 Para mayor información sobre el estilo de Pereda y recientes atribuciones consúltese Urrea, 2019: 108-118 y Quesada, 2018: 142-143.

8 Alonso de Arco, el «Sordillo de Pereda», fue un discípulo directo del pintor que debió entrar a trabajar en su taller hacia 1660. Pascual, 2018: 122-149.

\section{Bibliografía}

AGULLÓ Y COBO, Mercedes (1978), Noticias sobre pintores madrileños de los siglos XVI y XVII, Universidad de Granada, Granada. ANGULO ÍÑIGUEZ, Diego (1957), «Pereda: Judit y Holofernes», Archivo Español de Arte, n. 29, pp. 125-126.

ANGULO ÍÑIGUEZ, Diego y PÉREZ SÁNCHEZ, Alfonso E. (1983), Historia de la pintura española. La escuela madrileña del segundo tercio del siglo XVII, Instituto Diego Velázquez, Madrid.

ATERIDO FERNÁNDEZ, Ángel (1997), «Mecenas y fortuna del pintor Antonio de Pereda», Archivo Español de Arte, vol. 70, n. ${ }^{\circ} 279$, pp. $271-284$

BLANCO MOZO, Juan Luis (1998), «Algo más en torno del equipaje ideológico y material de Giovanni Battista Crescenzi», en BÉRCHEZ, Joaquín, GÓMEZ-FERRER LOZANO, Mercedes, SERRA DESFILIS, Amadeo (coords.), El Mediterráneo y el Arte Español: Actas del XI Congreso del CEHA, Valencia.

BURKE, Marcus B. y CHERRY, Peter (1997), Collections of Paintings in Madrid, 1601-1755, Getty Publications, Los Ángeles.

CALVO CASTELLÓN, Antonio (1988), «Iconografía del Antiguo Testamento en la pintura de los grandes maestros del barroco andaluz», Cuadernos de Arte e Iconografía, n. ${ }^{\circ}$ 1, pp. 135-157.

CHERRY, Peter (1987), «La intervención de Juan Bautista Crescenzi y las pinturas de Antonio de Pereda en un retablo perdido (1634)», Archivo Español de Arte, vol. 60, n. ${ }^{2} 239$, pp. 299-306.

CRUZ VALDOVINOS, José Manuel (1997), «A propósito de Cuevas, el pintor», Academia: Boletín de la Real Academia de Bellas Artes de San Fernando, n. ${ }^{\circ} 84$, pp. 365-382.

MARÍAS, Fernando (2016), «Sobre los problemas de los artistas conversos en el Siglo de Oro», en FRANCO LLOPIS, Borja, POMARA SAVERINO, Bruno, LOMAS CORTÉS, Manuel y RUIZ BEJARANO, Bárbara (eds.), Identidades cuestionadas. Coexistencias y conflictos interreligiosos en el Mediterráneo (ss. XIV-XVII), Universitat de Valencia, Valencia, pp. 425-447.

MARTÍ Y MONSÓ, José (1992), Estudios histórico-artísticos relativos principalmente a Valladolid, Edición en Colaboración, Valladolid. NAVARRETE PRIETO, Benito (2008), Fuentes y modelos de la pintura barroca madrileña, Arco/Libros, Madrid.

PALOMINO Y VELASCO, Antonio (1988), El museo pictórico y la escala óptica. El parnaso español pintoresco y laureado, Aguilar, Madrid.

PASCUAL CHENEL, Álvaro (2018), «Alonso del Arco y Antonio Castrejón, pintores madrileños del siglo XVIl: nuevas incorporaciones a sus catálogos», Imafronte, n. ${ }^{\circ}$ 25, pp. 121-149.

PÉREZ SÁNCHEZ, Alfonso E. (1978), D. Antonio de Pereda (1611-1678) y la pintura madrileña de su tiempo: salas de Exposiciones del Palacio de Bibliotecas y Museos, Publicación del Patronato Nacional de Museos, Madrid.

QUESADA, José María (2018), «El San Miguel arcángel perdido de Antonio de Pereda», Ars Magazine, n. 37, pp. $142-143$.

TORMO Y MONZÓ, Elías (1916), Un gran pintor vallisoletano: Antonio de Pereda. La vida del artista, Tipografía del Colegio de Santiago, Valladolid.

URREA FERNÁNDEZ, Jesús (1976), «Antonio de Pereda nació en 1611», Archivo Español de Arte, vol. 49, n. ${ }^{0} 195$, pp. $336-337$. 
URREA FERNÁNDEZ, Jesús (1995), «Noticias familiares del pintor Antonio Pereda», Archivo Español de Arte, n. ${ }^{\circ} 269$, pp. 80-81.

- (2018), «El cielo de los Monterrey», Ars Magazine, n. ${ }^{\circ}$ 41, pp. 108-118.

URREA FERNÁNDEZ, Jesús y VALDIVIESO GONZÁLEZ, Enrique (2017), Pintura barroca vallisoletana, Editorial Universidad de Sevilla, Sevilla.

VALVERDE MADRID, Antonio (1978), «En el Centenario del pintor Antonio de Pereda», Boletín de la Academia de Bellas Artes, n. ${ }^{\circ} 6$, pp. 202-220. 